\title{
Circumstantial impass in our Scientific Publishing
}

This difficult situation of supporting Brazilian science is taking the scientific community to a certain despair as to their prospects. Not that this situation is a current problem, however it has been getting serious. For several years the problems of reducing funds to perform researches is on behalf of the governments' responsibility to attend the demands of resources in the area, has truly become worse in the past two years. For this reason, such important programs on International Scientific Exchange, such as, "Science without Borders" where in the beginning, these programs were surrounded by great hopes for having the possibility of opening new academic centers along with Brazilian university students, integrating other centers in the United States and Europe, which unfortunately discontinued prematurely, frustrating many $\mathrm{PhD}$ and Post-Graduate students. In addition, these fund reductions for research projects and also the reduction of scholarships even within the country had to end one of the virtuous cycles, an extremely undesirable perspective for science in Brazil. There is no need to say that these programs have been strongly dependent on the work from the Post-Graduate courses. In a country in which financial support for research is almost entirely from the Public Authorities and this fact brings consequences and most of them are serious. There is a great probability of a decrease in scientific publications, in which provides excellence in researches from centers and Post-Graduate courses. The quantity and quality of the articles ready to be published, depends only on the conditions that certainly will reflect on its fault and virtue. It may reduce not only the quality but perhaps the number of issues and perhaps the creation of new scientific journals. It is not idle to remember a classical example associating between scientific production and publication which demonstrates the exponential growth in a scientific period and the development of modern science from the end of the $16^{\text {th }}$ century until the $20^{\text {th }}$ century. ${ }^{1}$ In other words, the period in which science multiplied in quantity and quality, its communication was driven in a similar process. However what is most notable is that the development of this phenomenon occurred precisely when another movement was present as an even more basic foundation: the boom of the industrial revolution and mercantile in that historical period. So, see the connection to expand, the circulation of the money and the expansion of science.

The consequence is that the richest countries produce more scientific issues and publish more. And a positively retrogression system becomes evident with scientific production by publishing more and empowering science to perform more activities.

These considerations can help to predict two difficulties in the inclusion of the world of science in terms of quality. One of them refers to the insertion of Brazilian articles in journals indexed in major international reference databases as the Institute of Scientific Information (ISI) where journals present their impact factor. In this aspect, Brazil demonstrated a strong and continued evolution from 1980 to 2009, when it reached the 13th place in the world's ranking.

The other aspect that also showed evolution refers to the number of issues edited in Brazil and indexed by the ISI that in 2014 dropped to $124 .^{2}$

Therefore the country has shown growth capacity in the area of scientific publication, when there was condition to do so, however the Brazilian articles had to stop producing as well as participating in the international ranking. We do not know about the possible increase in the number of national journals indexed in the coming years, but the expectation is not one of the best. Although, we should not disregard the ability of our managers in the National Council for Scientific and Technological Development (CNPq), the Scientific Electronic Library Online (SciELO) and the Brazilian Association of Scientific Editors (ABEC) that will try to do everything as possible, of course, so that our science does not follow the path downhill. 


\section{References}

1. Mabe MA. The number and growth. Serials. 2003; 16 (2): 191-7.

2. ABEC (Associação Brasileira de Editores Científicos). Fator de Impacto dos Periódicos Nacionais - 2014-2015. [acesso em 29 set 2016]. Disponível em: http://www.abecbrasil.org.br/includes/noticias/arquivos/jcr2014_15.pdf

José Eulálio Cabral Filho 1

1 Executive Editor. Brazilian Journal of Mother and Child Health. Recife, Pernambuco, Brazil. 